\title{
Determination of representative volume element in concrete under tensile deformation
}

\author{
Ł. Skarżyński and J. Tejchman* \\ Faculty of Civil and Environmental Engineering, Gdańsk University of Technology, Gdańsk, Poland \\ (Received July 25, 2010, Revised February 10, 2011, Accepted April 7, 2011)
}

\begin{abstract}
The 2D representative volume element (RVE) for softening quasi-brittle materials like concrete is determined. Two alternative methods are presented to determine a size of RVE in concrete subjected to uniaxial tension by taking into account strain localization. Concrete is described as a heterogeneous threephase material composed of aggregate, cement matrix and bond. The plane strain FE calculations of strain localization at meso-scale are carried out with an isotropic damage model with non-local softening.
\end{abstract}

Keywords: characteristic length; concrete; heterogeneous material; representative volume element (RVE); damage mechanics; softening; strain localization.

\section{Introduction}

To realistically capture the mechanism of localized zones in quasi-brittle materials, material microstructure has to be taken into account (Nielsen et al. 1995, Bažant and Planas 1998, Sengul et al. 2002, Lilliu and van Mier 2003, Kozicki and Tejchman 2008, He 2010, Skarżyński and Tejchman 2010). Such numerical description of strain localization is always connected with a huge number of finite or discrete elements and a related large computational effort. To practically solve this problem (by decreasing the number of elements in large concrete elements), some homogenization-based multi-scale models are used, where each macroscopic point at the coarse (large) scale is connected with a microscopic cell at the fine (small) scale. Thus, the most important issue in multi-scale analyses is determination of an appropriate size for a micro-structural model, so-called representative volume element RVE. The size of RVE should be chosen such that homogenized properties become independent of micro-structural variations and a micro-structural domain is small enough such that separation of scales is guaranteed. Many researchers attempted to define the size of RVE in heterogeneous materials with a softening response in a post-peak regime (Hill 1963, Bažant and Pijauder-Cabot 1989, Drugan and Willis 1996, Evesque 2000, van Mier 2000, Bažant and Novak 2003, Kanit et al. 2003, Kouznetsova et al. 2004, Gitman et al. 2007, Skarżyński and Tejchman 2009). The last outcomes in this topic show, however, that RVE cannot be defined in softening quasi-brittle materials due to strain localization since the material loses then its statistical homogeneity (Gitman et al. 2007, Skarżyński and Tejchman 2009, 2010). Thus, each multi-scale approach always suffers from non-objectivity of results with respect to a cell size (Gitman et al. 2008). RVE solely exists for linear and hardening regimes.

\footnotetext{
* Corresponding author, Professor, E-mail: tejchmk@pg.gda.pl
} 
The intention of our FE investigations is to determine RVE in concrete under tension using two alternative strategies (one of them was proposed by Nguyen et al. 2010). Concrete was assumed at meso-scale as a random heterogeneous material composed of three phases: aggregate, cement matrix and bond. The FE calculations of strain localization were carried out with a scalar isotropic damage with non-local softening.

\section{Constitutive model for concrete}

A simple isotropic damage continuum model was used describing the material degradation with the aid of only a single scalar damage parameter $D$ growing monotonically from zero (undamaged material) to one (completely damaged material) (Katchanov 1986, Simo and Ju 1987). The stressstrain function is represented by the following relationship

$$
\sigma_{i j}=(1-D) C_{i j k l}^{e} \varepsilon_{k l}
$$

where $C_{i j k l}^{e}$ is the linear elastic material stiffness matrix and $\varepsilon_{k l}$ is the strain tensor (' $e$ '-elastic). The loading function of damage is as follows

$$
f(\tilde{\varepsilon}, \kappa)=\tilde{\varepsilon}-\max \left\{\kappa, \kappa_{0}\right\}
$$

where $\kappa_{0}$ denotes the initial value of $\kappa$ when damage begins. If the loading function $f$ is negative, damage does not develop. During monotonic loading, the parameter $\kappa$ grows (it coincides with $\tilde{\varepsilon}$ ) and during unloading and reloading it remains constant. A Rankine failure type criterion was assumed to define the equivalent strain measure $\tilde{\varepsilon}$ (Jirasek and Marfia 2005)

$$
\tilde{\varepsilon}=\frac{\max \left\{\sigma_{i}^{e f f}\right\}}{E}
$$

where $E$ denotes the modulus of elasticity and $\sigma_{i}^{\text {eff }}$ are the principal values of the effective stress tensor

$$
\sigma_{i j}^{e f f}=C_{i j k l}^{e} \varepsilon_{k l}
$$

If all principal stresses are negative, the loading function $f$ is negative and no damage takes place.

To describe the evolution of the damage parameter $D$ (determining the shape of the softening curve under tension), the exponential softening law was used (Peerlings et al. 1998)

$$
D=1-\frac{\kappa_{0}}{\kappa}\left(1-\alpha+\alpha e^{-\beta\left(\kappa-\kappa_{0}\right)}\right)
$$

where $\alpha$ and $\beta$ are the material constants.

The constitutive isotropic damage model for concrete requires the following 5 material constants: $E, v, \kappa_{0}, \alpha$ and $\beta$. The model is suitable for tensile failure (Marzec et al. 2007, Skarżyński et al. 2009) and mixed tensile-shear failure (Bobiński and Tejchman 2010). However, it cannot realistically describe irreversible deformations, volume changes and shear failure (Simone and Sluys 2004).

To properly describe strain localization, to preserve the well-possedness of the boundary value problem, to obtain mesh-independent results and finally to include a characteristic length of microstructure $l_{c}$ in simulations (which sets the width of a localized zone), an integral-type non-local theory was used as a regularization technique (Bažant and Jirasek 2002, Bobiński and Tejchman 
2004). The equivalent strain measure $\tilde{\varepsilon}$ was replaced by its non-local value (Pijauder-Cabot and Bažant 1987) to evaluate the loading function (Eq. (2)) and to calculate the damage threshold parameter $\kappa$

$$
\bar{\varepsilon}=\frac{\int_{V} \omega(\|x-\xi\|) \tilde{\varepsilon}(\xi) d \xi}{\int_{V} \omega(\|x-\xi\|) d \xi}
$$

where $V$-the body volume, $x$ - the coordinates of the considered (actual) point, $\xi$-the coordinates of surrounding points and $\omega$-the weighting function. As a weighting function $\omega$, a Gauss distribution function was used

$$
\omega(r)=\frac{1}{l_{c} \sqrt{\pi}} e^{-\left(\frac{r}{l_{c}}\right)^{2}}
$$

where $l_{c}$ denotes a characteristic length of micro-structure and the parameter $r$ is a distance between two material points. The averaging in Eq. (7) is restricted to a small representative area around each material point (the influence of points at the distance of $r=3 \times l_{\mathrm{c}}$ is only $0.01 \%$ ). A characteristic length is usually related to material micro-structure and is determined with an inverse identification process of experimental data (Le Bellěgo et al. 2003).

\section{Input data}

The FE investigations were performed with concrete described as a three-phase material composed of the cement matrix, aggregate and interfacial transition (contact) zones between the cement matrix and aggregate (the material constants for each phase are given in Table 1). The interface was assumed to be the weakest component (Lilliu and van Mier 2003) and its width was $0.25 \mathrm{~mm}$ (Gitman et al. 2007). For the sake of simplicity, the aggregate was assumed in the form of circles. The number of triangular finite elements changed between 4,000 (the smallest specimen) and 100,000 (the largest specimen). The size of triangular elements was: $s_{a}=0.5 \mathrm{~mm}$ (aggregate), $s_{c m}=$ $0.25 \mathrm{~mm}$ (cement matrix) and $s_{i t z}=0.1 \mathrm{~mm}$ (interface). To analyze the existence of RVE under tension, a plane strain uniaxial tension test (Fig. 1) was performed with a quadratic concrete specimen representing a unit cell with the periodicity of boundary conditions and material periodicity (Fig. 2) (Gitman et al. 2007, Skarżyński and Tejchman 2010).

The unit cells of six different sizes were investigated $b \times h: 5 \times 5 \mathrm{~mm}^{2}, 10 \times 10 \mathrm{~mm}^{2}, 15 \times 15 \mathrm{~mm}^{2}$,

Table 1 Material properties assumed for FE calculations of 2D random heterogeneous three-phase concrete material

\begin{tabular}{lccc}
\hline \multicolumn{1}{c}{ Parameters } & Aggregate & Cement matrix & ITZ \\
\hline Modulus of elasticity $E[\mathrm{GPa}]$ & 30 & 25 & 20 \\
Poisson's ratio $v[-]$ & 0.2 & 0.2 & 0.2 \\
Crack initiation strain $\kappa_{0}[-]$ & 0.5 & $8 \times 10^{-5}$ & $5 \times 10^{-5}$ \\
Residual stress level $\alpha[-]$ & 0.95 & 0.95 & 0.95 \\
Slope of softening $\beta[-]$ & 200 & 200 & 200 \\
\hline
\end{tabular}




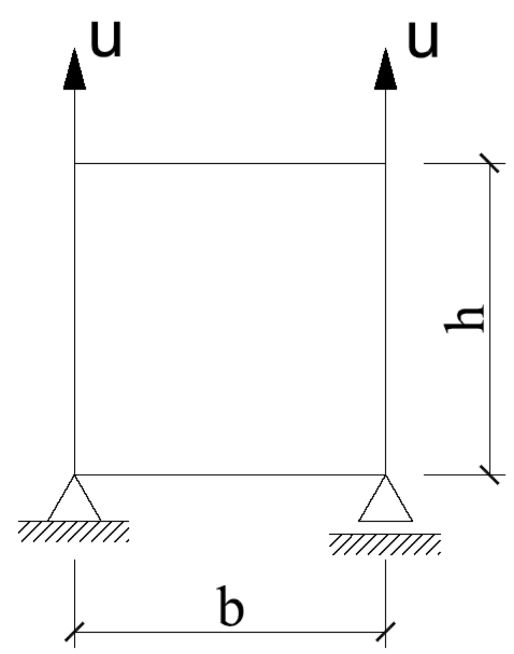

Fig. 1 Uniaxial tension test (schematically)

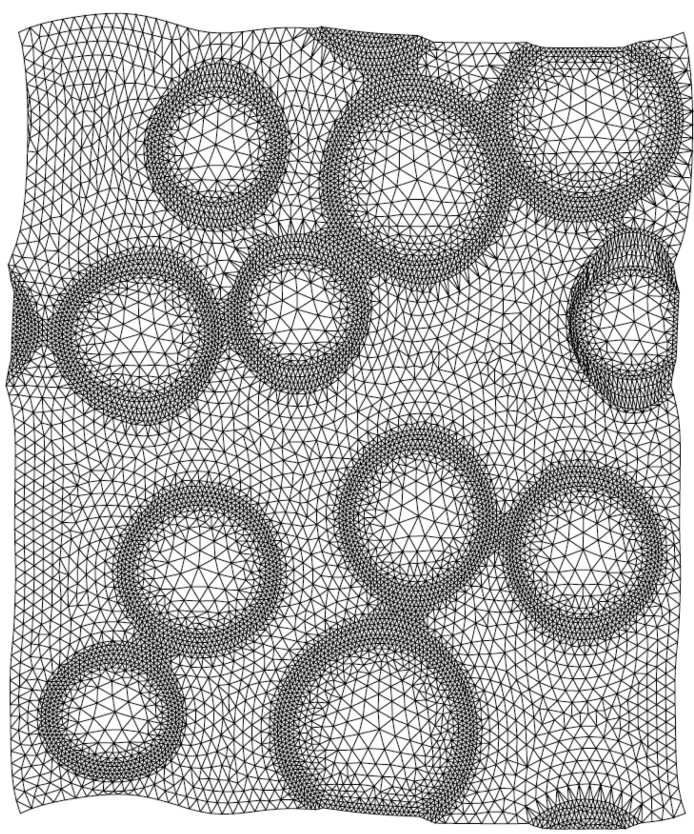

Fig. 2 Deformed three-phase concrete specimen with periodicity of boundary conditions and material periodicity

$20 \times 20 \mathrm{~mm}^{2}, 25 \times 25 \mathrm{~mm}^{2}$ and $30 \times 30 \mathrm{~mm}^{2}$, respectively. For each specimen, three different stochastic realizations were performed (Fig. 3) with the aggregate density of $\rho=30 \%$ (the results for $\rho=45 \%$ and $\rho=60 \%$ showed the same trend). A characteristic length of micro-structure was assumed to be $l_{c}=1.5 \mathrm{~mm}$ on the basis of comparative experimental measurements using a Digital Image Correlation technique (Skarżyński et al. 2009) and numerical studies with an isotropic damage model (Skarżyński and Tejchman 2010). Thus, the maximum finie element size in 3 different concrete phases was not greater than $3 \times l_{c}$ to obtain mesh-objective results (Bobiński and Tejchman 2004, Marzec et al. 2007).

\section{Numerical results for uniaxial tension}

\subsection{Standard averaging approach}

The standard averaging is performed in the entire specimen domain. The homogenized stress and strain are defined in two dimensions as

$$
\langle\sigma\rangle=\frac{f_{y}^{\text {int }}}{b} \text { and }\langle\varepsilon\rangle=\frac{u}{h}
$$

where $f_{y}^{\text {int }}$ denotes the sum of all vertical nodal forces in the ' $y$ ' direction along the top edge of the specimen (Fig. 1), $u$ is the prescribed vertical displacement in the ' $y$ ' direction and $b$ and $h$ are the width and height of the specimen. 


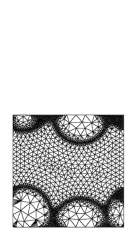

(a)

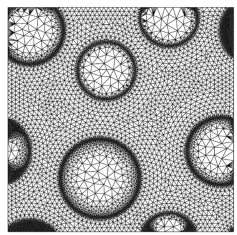

(b)

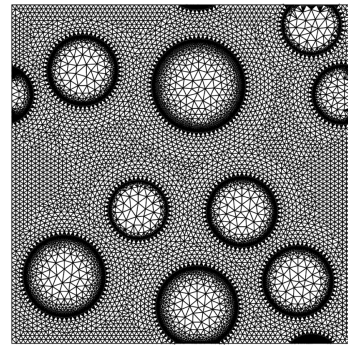

(c)

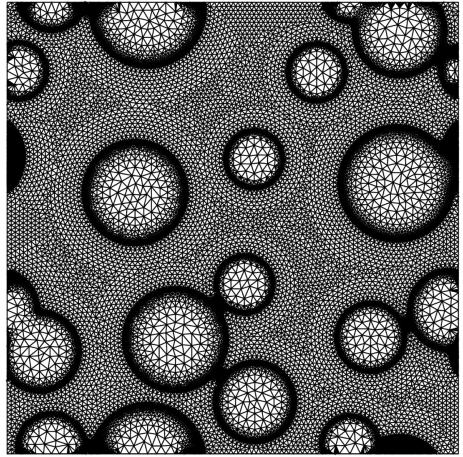

(d)

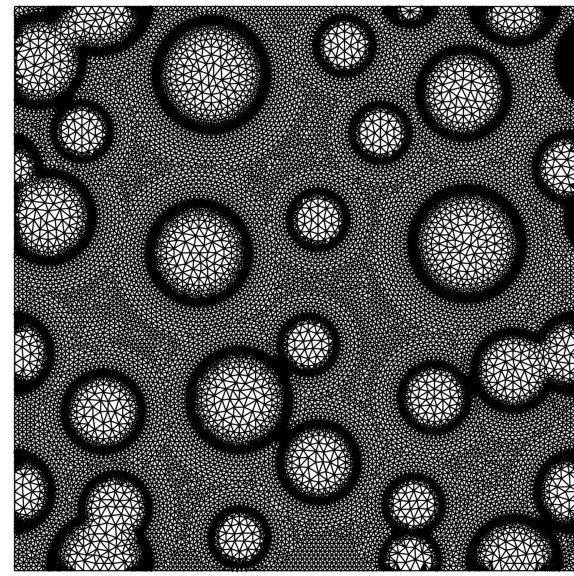

(e)

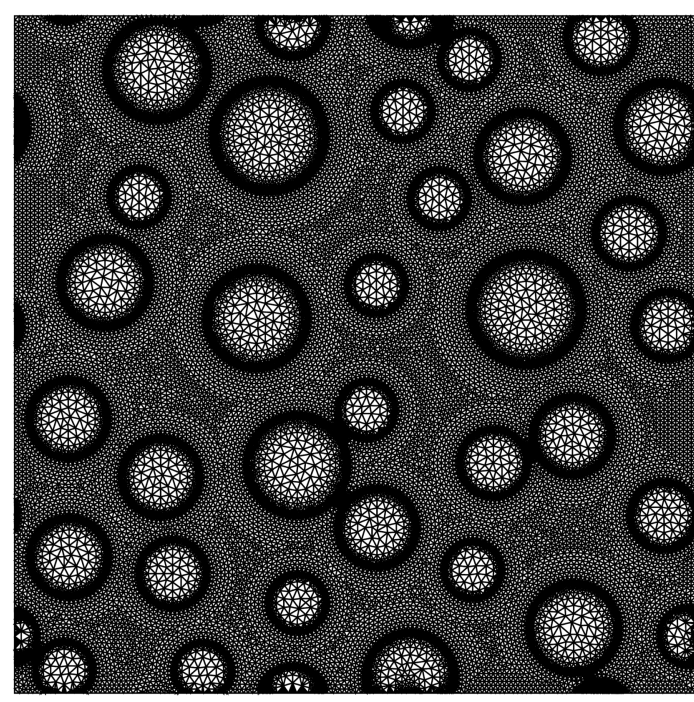

(f)

Fig. 3 Concrete specimens of different size: (a) $5 \times 5 \mathrm{~mm}^{2}$, (b) $10 \times 10 \mathrm{~mm}^{2}$, (c) $15 \times 15 \mathrm{~mm}^{2}$, (d) $20 \times 20$ $\mathrm{mm}^{2}$, (e) $25 \times 25 \mathrm{~mm}^{2}$ and (f) $30 \times 30 \mathrm{~mm}^{2}$ (aggregate density $\rho=30 \%$ )

Fig. 4 presents the stress-strain relationships for various cell sizes and two random aggregate distributions with the material constants of Table $1\left(l_{c}=1.5 \mathrm{~mm}\right)$. In the first case, the aggregate distribution was similar and in the second case it was at random in different unit cells. The results show that the stress-strain curves are the same solely in an elastic regime independently of the specimen size, aggregate density and aggregate distribution. However, they are completely different at the peak and in a softening regime. An increase of the specimen size causes a strength decrease and an increase of material brittleness (softening rate) (Fig. 4). The differences in the evolution of stress-strain curves in a softening regime are caused by strain localization (in the form of a curved localized zone propagating between aggregates, Figs. 5 and 6) contributing to a loss of material homogeneity (due to the fact that strain localization is not scaled with increasing specimen size). The width of a calculated localized zone is approximately $w_{c}=3 \mathrm{~mm}=2 \times l_{c}=12 \times s_{c m}$ (unit cell $5 \times 5 \mathrm{~mm}^{2}$ ), $w_{c}=5 \mathrm{~mm}=3.33 \times l_{c}=20 \times s_{c m}$ (unit cell $10 \times 10 \mathrm{~mm}^{2}$ ) and $w_{c}=6 \mathrm{~mm}=4 \times l_{c}=24 \times s_{c m}$ 


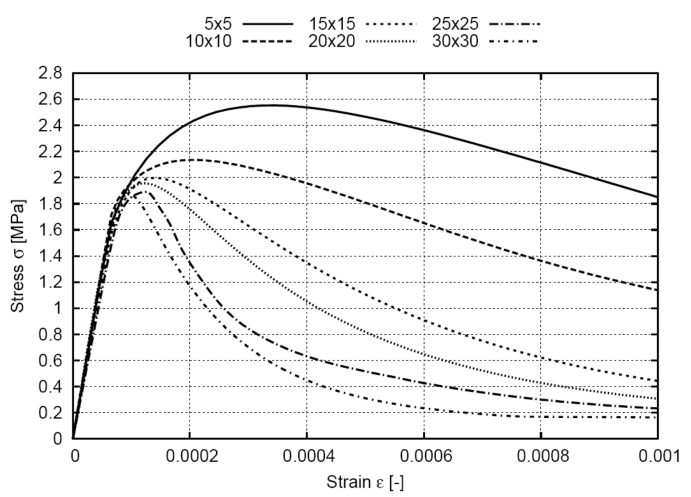

(a)

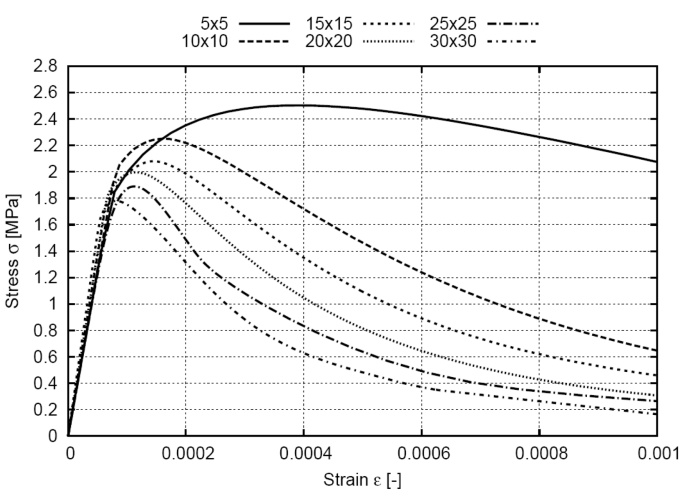

(b)

Fig. 4 Stress-strain curves for various sizes of concrete specimens and two different random distributions of aggregate (a) and (b) using standard averaging procedure (characteristic length $l_{c}=1.5 \mathrm{~mm}$, aggregate density $\rho=30 \%$ )

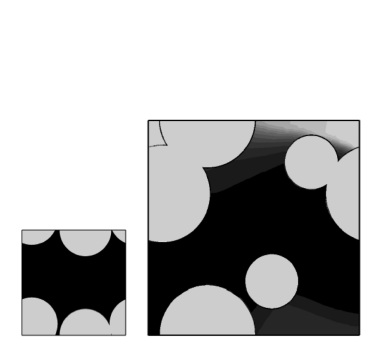

(a)

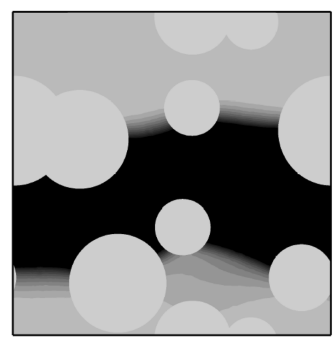

(c)

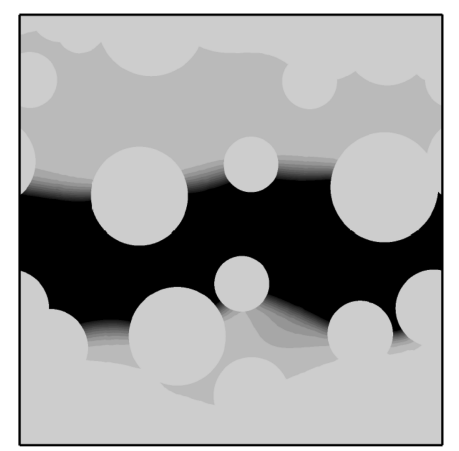

(d)

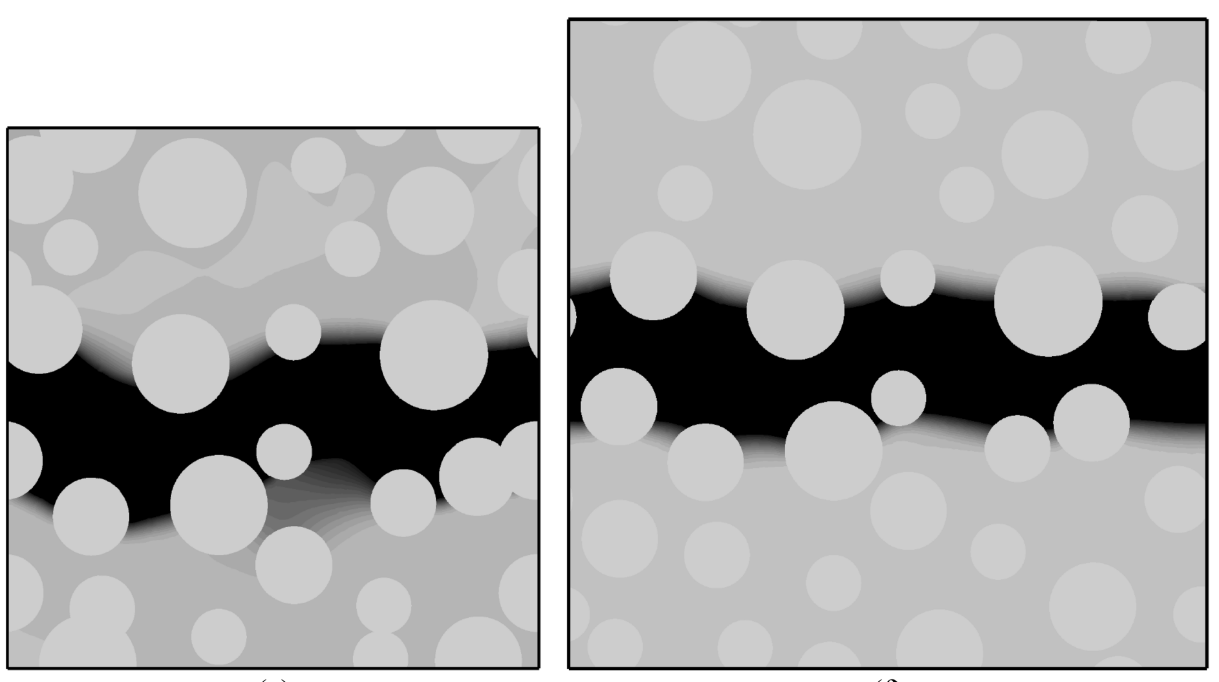

(e)

(f)

Fig. 5 Distribution of non-local softening strain measure for various specimen sizes and stress-strain curves of Fig. 4(a) using standard averaging procedure (characteristic length $l_{c}=1.5 \mathrm{~mm}$, aggregate density $\rho=30 \%$ ) 


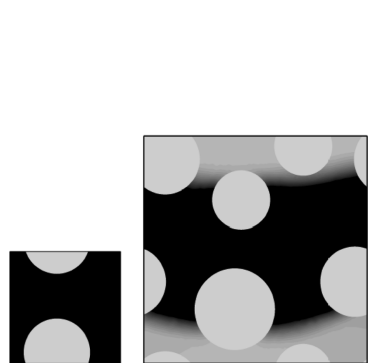

(a)

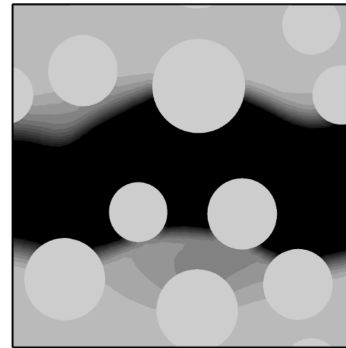

(c)

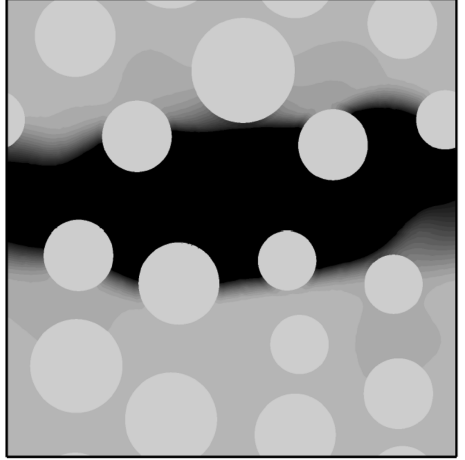

(d)

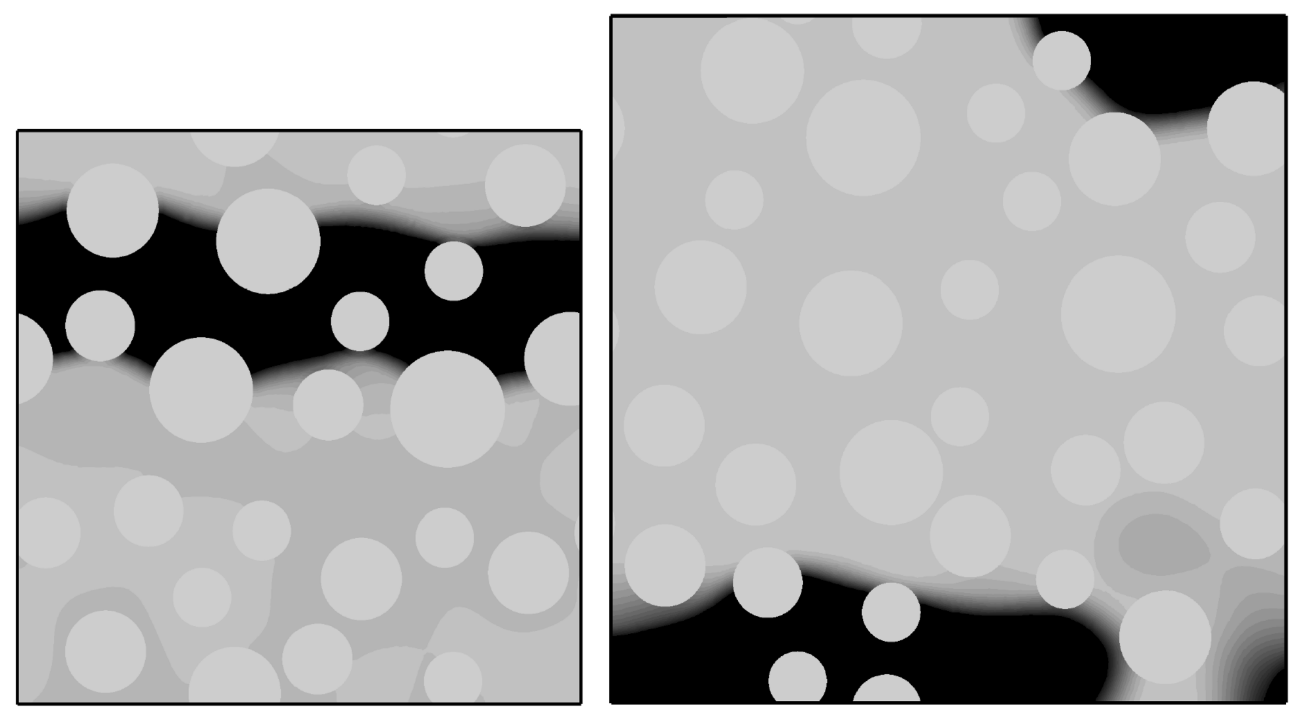

(e)

(f)

Fig. 6 Distribution of non-local softening strain measure for various specimen sizes and stress-strain curves of Fig. 4(b) using standard averaging procedure (characteristic length $l_{c}=1.5 \mathrm{~mm}$, aggregate density $\rho=30 \%)$

(unit cells larger than $10 \times 10 \mathrm{~mm}^{2}$ ).

Fig. 7 presents the expectation value and standard deviation of the tensile fracture energy $G_{f}$ versus the specimen height $h$ for 3 different realizations. The fracture energy $G_{f}$ was calculated as the area under the strain-stress curves $g_{f}$ multiplied by the width of a localized zone $w_{c}$

$$
G_{y}=g_{f} \times w_{c}=\left(\int_{a_{1}}^{a_{2}}\langle\sigma\rangle d\langle\varepsilon\rangle\right) \times w_{c}
$$

The integration limits ' $a_{1}$ ' and ' $a_{2}$ ' are 0 and 0.001 , respectively (Fig. 4). The fracture energy decreases with increasing specimen size without reaching an asymptote, i.e. the size dependence of RVE exists (since a localized zone does not scale with the specimen size). Thus, RVE cannot be found for softening materials and a standard averaging approach cannot be used in homogenization- 


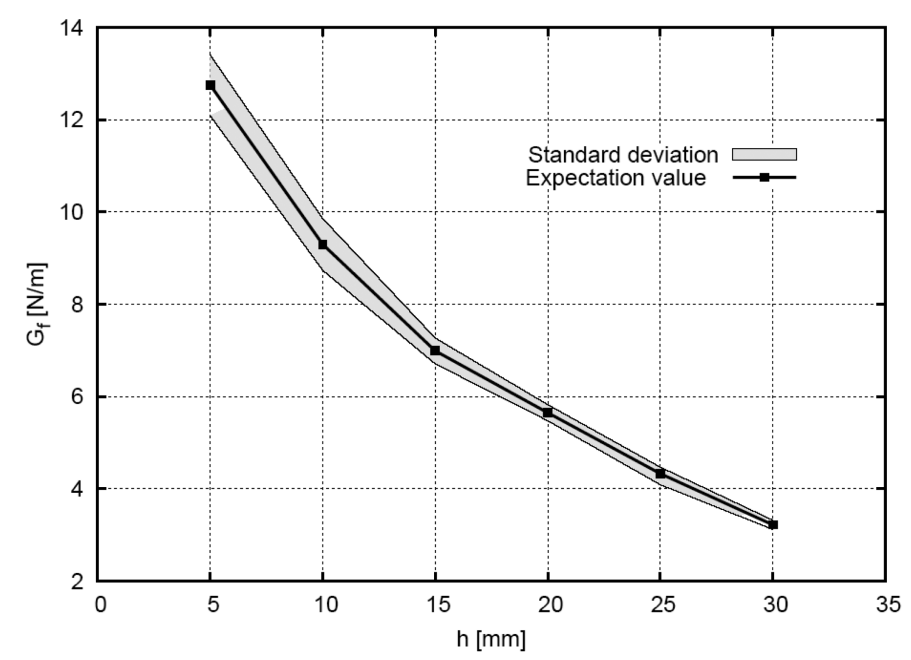

Fig. 7 Expected value and standard deviation of tensile fracture energy $G_{f}$ versus specimen height $h$ using standard averaging (aggregate density $\rho=30 \%$ )

based multiscale models.

\subsection{Localized zone averaging approach}

Recently, the existence of RVE for softening materials was proved (based on Hill's averaging principle) for cohesive and adhesive failure by deriving a traction-separation law (for a macro crack) instead of a stress-strain relation from microscopic stresses and strains (Verhoosel et al. 2010a, 2010b). This was indicated by the uniqueness (regardless of a micro sample size) of a macro traction-separation law which was obtained by averaging responses along propagating micro discrete cracks. Prompted by this approach and the fact that a localized zone does not scale with the micro specimen size, Nguyen et al. (2010) proposed an approach where homogenized stress and strain were averaged over a localized strain domain in softening materials rather (which is small compared with the specimen size) than over the entire specimen. We used this method in this paper. In this approach, the homogenized stress and strain are

$$
\langle\sigma\rangle=\frac{1}{A_{z_{A_{z}}}} \int_{m} \sigma_{m} d A_{z} \text { and }\langle\varepsilon\rangle=\frac{1}{A_{z_{A_{z}}}} \int_{\varepsilon_{m}} d A_{z}
$$

where $A_{z}$ is the localized zone area and $\sigma_{m}$ and $\varepsilon_{m}$ are the meso-stress and meso-strain, respectively. The localized zone area $A_{z}$ is determined on the basis of a distribution of the non-local equivalent strain measure $\bar{\varepsilon}$ (Eq. (6)). As the cut-off value $\bar{\varepsilon}_{\min }=0.005$ is always assumed at the maximum mid-point value usually equal to $\bar{\varepsilon}_{\max }=0.007-0.011$. Thus, a linear material behaviour is simply swept out (which causes the standard stress-strain diagrams to be specimen size dependent), and an active material plastic response is solely taken into account.

Fig. 8 presents the stress-strain relationships for various specimen sizes and two random aggregate distributions with the material constants from Table $1\left(l_{c}=1.5 \mathrm{~mm}\right)$ for the calculated localized zones of Figs. 5 and 6 . These stress-strain curves in a softening regime (for the unit cells larger than $\left.10 \times 10 \mathrm{~mm}^{2}\right)$ are in very good accordance with respect to their shape. In this case, the statistically 


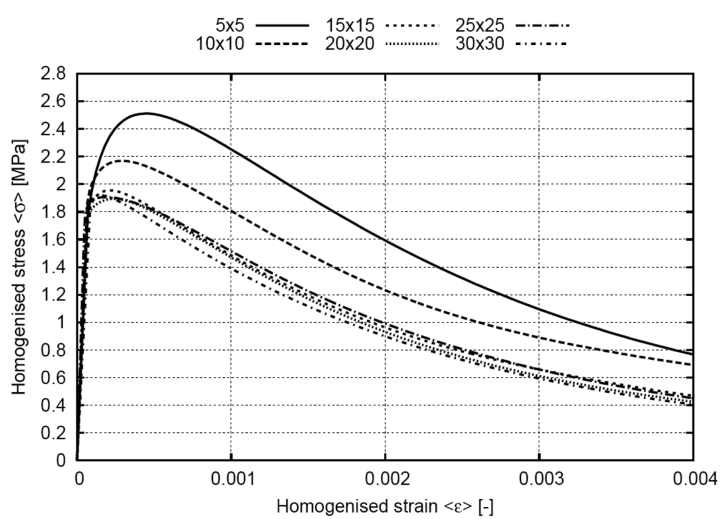

(a)

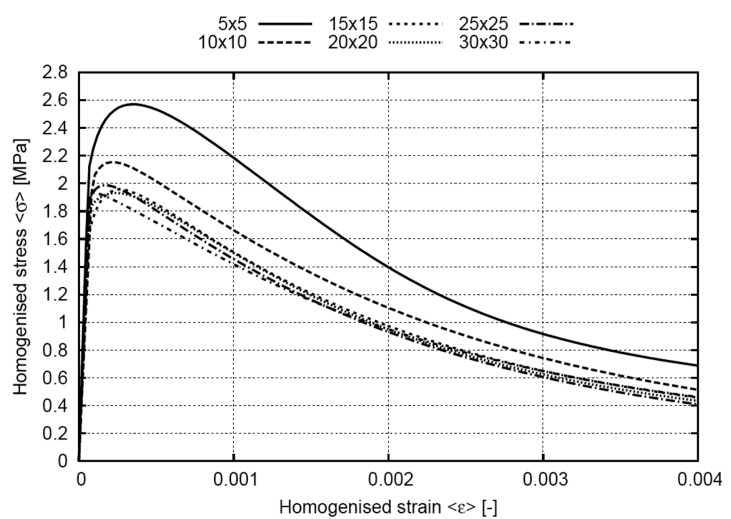

(b)

Fig. 8 Stress-strain curves for various sizes of concrete specimens and two different random distributions of aggregate (a) and (b) using localized zone averaging procedure (characteristic length $l_{c}=1.5 \mathrm{~mm}$, aggregate density $\rho=30 \%$ )

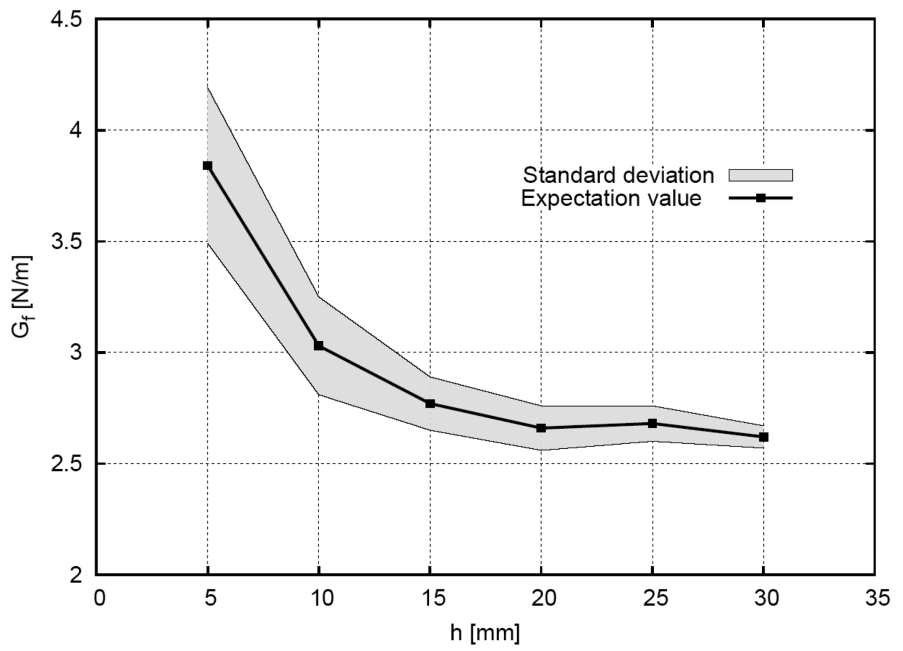

Fig. 9 Expected value and standard deviation of tensile fracture energy $G_{f}$ versus specimen height $h$ using localized zone averaging (aggregate density $\rho=30 \%$ )

representative volume element exists and is equal to $15 \times 15 \mathrm{~mm}^{2}$.

Fig. 9 presents the expectation value and standard deviation of the tensile fracture energy $G_{f}$ versus the specimen height $h$ for 3 different realizations. The integration limits were $a_{1}=0$ and $a_{2}=0.004$ (Eq. (9)). The fracture energy decreases with increasing specimen size approaching an asymptote when the cell size is $15 \times 15 \mathrm{~mm}^{2}$. Thus, the homogenized stress-strain relationships obtained are objective with respect to the micro sample size. RVE does not represent the entire material in its classical meaning, but the material in a localized zone. 


\subsection{Varying characteristic length approach}

With increasing characteristic length, both specimen strength and width of a localized zone increase. On the other hand, softening decreases and material behaves more ductile (Skarżyński and Tejchman 2009). Taking these two facts into account, a varying characteristic length related to the reference specimen size (assumed as $15 \times 15 \mathrm{~mm}^{2}$ or $30 \times 30 \mathrm{~mm}^{2}$ ) is introduced (to scale the width of a localized zone with varying specimen height) according to the formula

$$
l_{c}^{v}=l_{c}^{15 \times 15} \times \frac{h}{15}\left[\frac{\mathrm{mm}}{\mathrm{mm}}\right]
$$

or

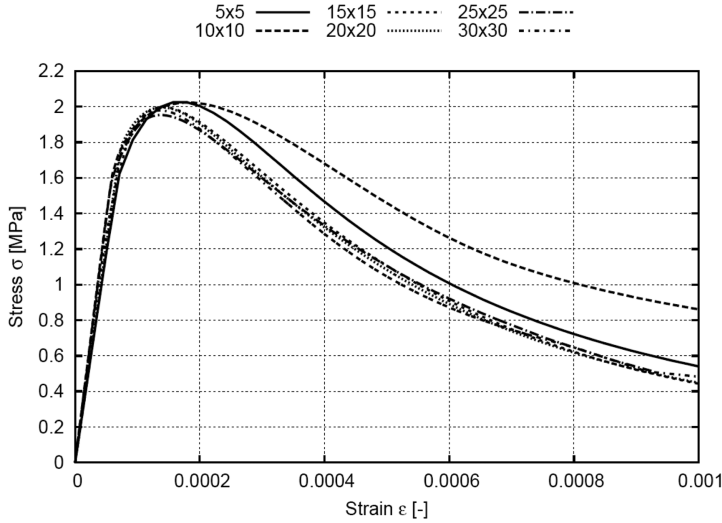

(a)

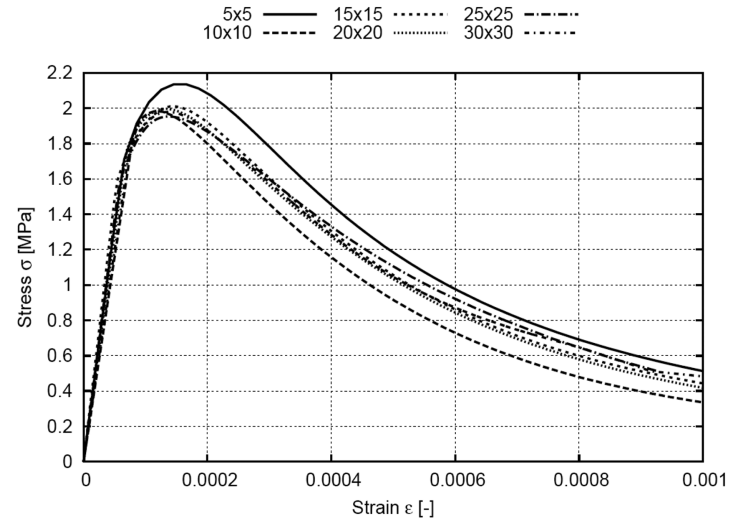

(b)

Fig. 10 Stress-strain curves for various sizes of concrete specimens and two different random distributions of aggregate (a) and (b) using varying characteristic length approach (reference unit size $15 \times 15 \mathrm{~mm}^{2}$, characteristic length according to Eq. (11), aggregate density $\rho=30 \%$ )

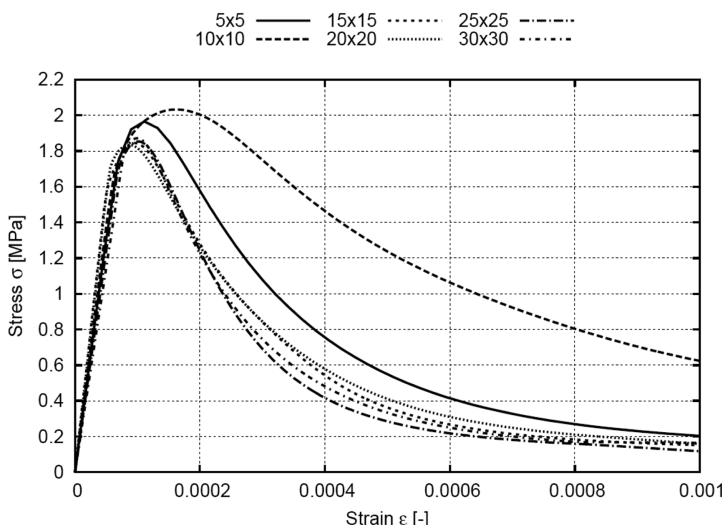

(a)

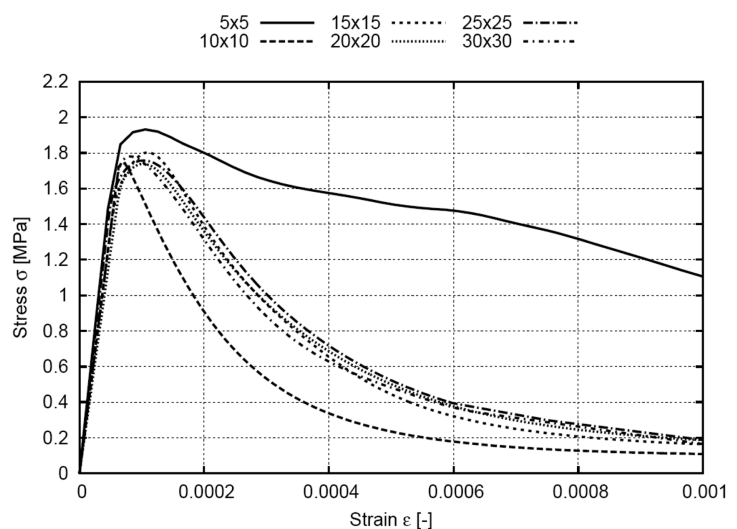

(b)

Fig. 11 Stress-strain curves for various sizes of concrete specimens and two different random distributions of aggregate (a) and (b) using varying characteristic length approach (reference unit size $30 \times 30 \mathrm{~mm}^{2}$, characteristic length according to Eq. (12), aggregate density $\rho=30 \%$ ) 


$$
l_{c}^{v}=l_{c}^{30 \times 30} \times \frac{h}{30} \frac{[\mathrm{mm}]}{[\mathrm{mm}]}
$$

where $l_{c}{ }^{15 \times 15}=l_{c}{ }^{30 \times 30}=1.5 \mathrm{~mm}$ is a characteristic length for the reference unit cell $15 \times 15 \mathrm{~mm}^{2}$ or $30 \times 30 \mathrm{~mm}^{2}$ and $h$ is the unit cell height. A larger unit cell than $30 \times 30 \mathrm{~mm}^{2}$ can be also used (the width of a localized zone in the reference unit cell cannot be too strongly influenced by boundary conditions, as e.g. the cell size smaller than $10 \times 10 \mathrm{~mm}^{2}$ ). The characteristic length $l_{c}^{v}$ is no longer a physical parameter related to non-local interactions in the damaging material, but an artificial parameter adjusted to the specimen size.

The stress-strain relationships for various specimen sizes and various characteristic lengths are shown in Figs. 10 and 11. A characteristic length varies between $l_{c}=0.5 \mathrm{~mm}$ for the unit cell $5 \times 5$ $\mathrm{mm}^{2}$ and $l_{c}=3.0 \mathrm{~mm}$ for the unit cell $30 \times 30 \mathrm{~mm}^{2}$ according to Eq. (11), and between $l_{c}=0.25 \mathrm{~mm}$

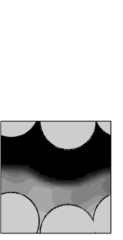

(a)

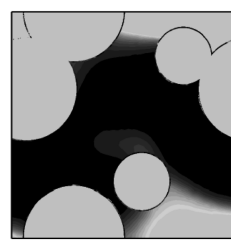

(b)

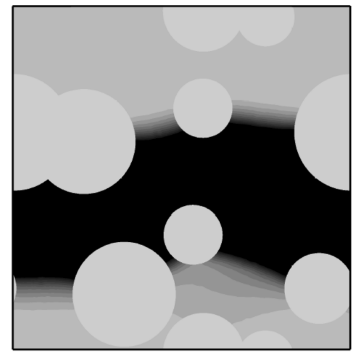

(c)

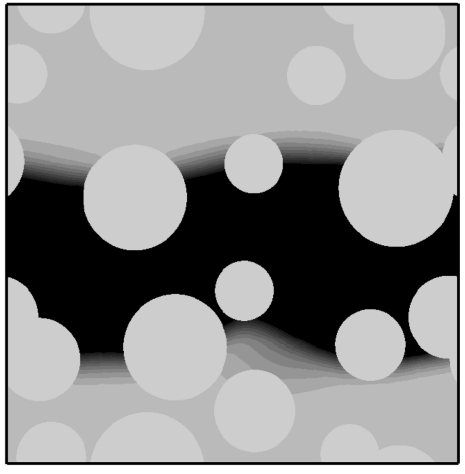

(d)

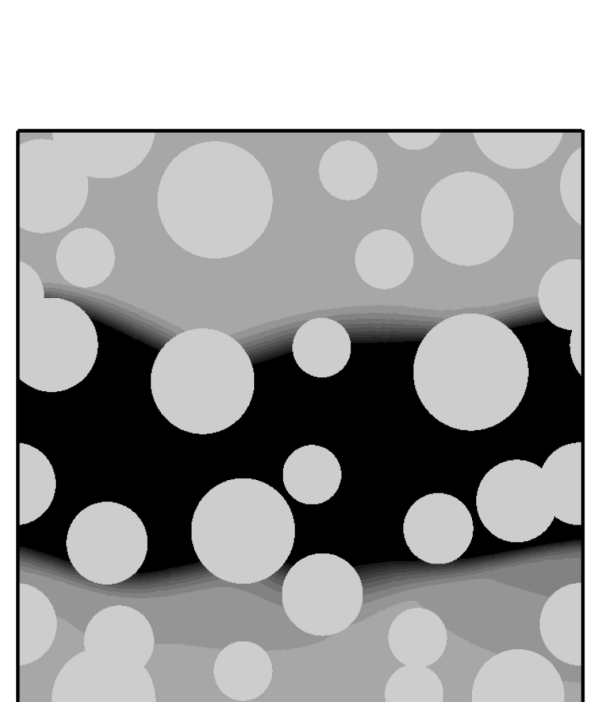

(e)

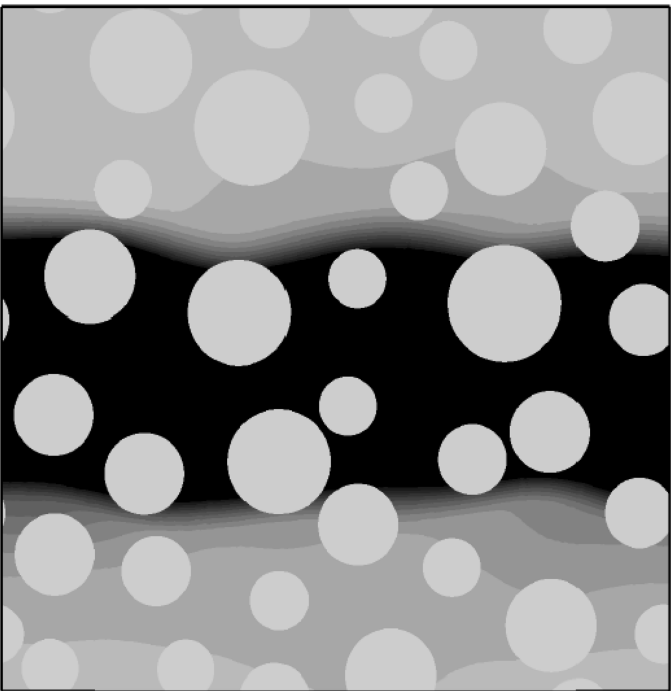

(f)

Fig. 12 Distribution of non-local softening strain measure for various specimen sizes and stress-strain curves from Fig. 10(a) using varying characteristic length approach (reference unit size $15 \times 15 \mathrm{~mm}^{2}$, characteristic length according to Eq. (11), aggregate density $\rho=30 \%$ ) 
for the unit cell $5 \times 5 \mathrm{~mm}^{2}$ and $l_{c}=1.5 \mathrm{~mm}$ for the unit cell $30 \times 30 \mathrm{~mm}^{2}$ according to Eq. (12). The width of a calculated localized zone (for the reference unit cell $15 \times 15 \mathrm{~mm}^{2}$ ) is approximately $w_{c}=2 \mathrm{~mm}=4 \times l_{c}=8 \times s_{c m}\left(\right.$ cell $\left.5 \times 5 \mathrm{~mm}^{2}\right), w_{c}=4 \mathrm{~mm}=4 \times l_{c}=16 \times s_{c m}\left(\right.$ cell $\left.10 \times 10 \mathrm{~mm}^{2}\right), w_{c}=6$ $\mathrm{mm}=4 \times l_{c}=24 \times s_{c m}\left(\right.$ cell $\left.15 \times 15 \mathrm{~mm}^{2}\right), w_{c}=8 \mathrm{~mm}=4 \times l_{c}=32 \times s_{c m}\left(\right.$ cell $\left.20 \times 20 \mathrm{~mm}^{2}\right), w_{c}=10$ $\mathrm{mm}=4 \times l_{c}=40 \times s_{c m}\left(\right.$ cell $\left.25 \times 25 \mathrm{~mm}^{2}\right)$ and $w_{c}=12 \mathrm{~mm}=4 \times l_{c}=48 \times s_{c m}$ (cell $\left.30 \times 30 \mathrm{~mm}^{2}\right)$ (Figs. 12 and 13). The width of a calculated localized zone (for the reference unit cell $30 \times 30 \mathrm{~mm}^{2}$ ) is approximately $w_{c}=1 \mathrm{~mm}=4 \times l_{c}=4 \times s_{c m}$ (cell $\left.5 \times 5 \mathrm{~mm}^{2}\right), w_{c}=2 \mathrm{~mm}=4 \times l_{c}=8 \times s_{c m}$ (cell $10 \times 10$ $\left.\mathrm{mm}^{2}\right), w_{c}=3 \mathrm{~mm}=4 \times l_{c}=12 \times s_{c m}\left(\right.$ cell $\left.15 \times 15 \mathrm{~mm}^{2}\right), w_{c}=4 \mathrm{~mm}=4 \times l_{c}=16 \times s_{c m}\left(\right.$ cell $\left.20 \times 20 \mathrm{~mm}^{2}\right)$, $w_{c}=5 \mathrm{~mm}=4 \times l_{c}=20 \times s_{c m}\left(\right.$ cell $\left.25 \times 25 \mathrm{~mm}^{2}\right)$ and $w_{c}=6 \mathrm{~mm}=4 \times l_{c}=24 \times s_{c m}\left(\right.$ cell $\left.30 \times 30 \mathrm{~mm}^{2}\right)$ (Figs. 14 and 15). A localized zone is scaled with the specimen size. Owing to that the material does not lose its homogeneity and its response during softening is similar for the cell $15 \times 15 \mathrm{~mm}^{2}$ and larger ones. Thus, the size of the representative volume element is again equal to $15 \times 15 \mathrm{~mm}^{2}$.

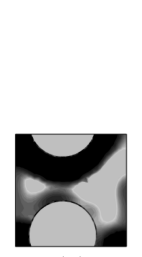

(a)

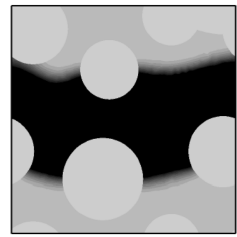

(b)

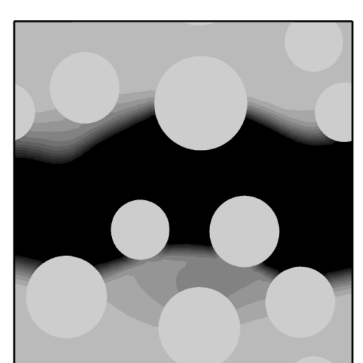

(c)

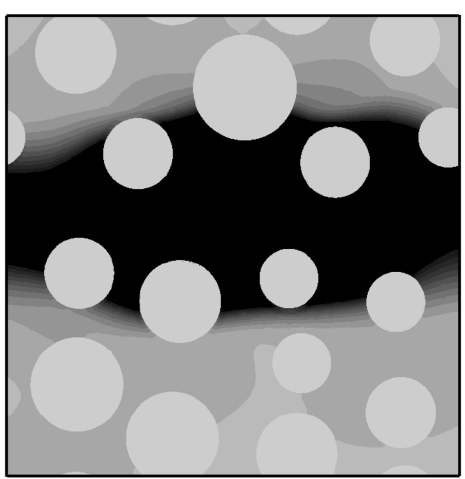

(d)

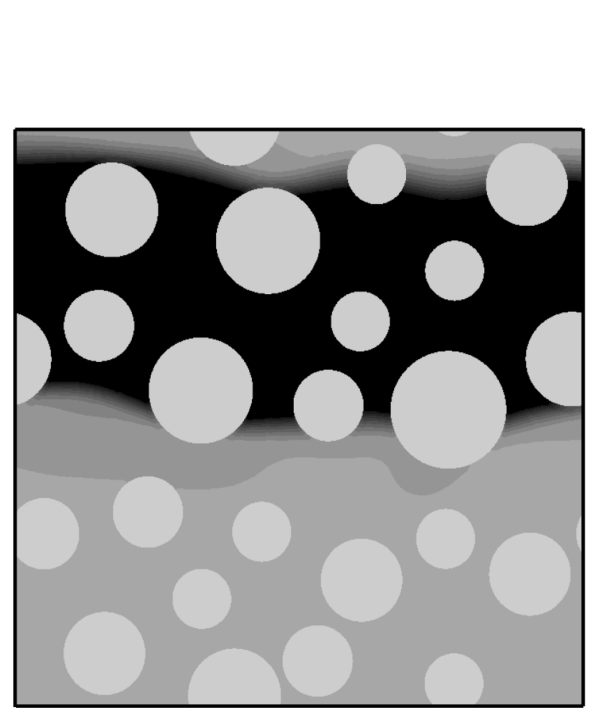

(e)

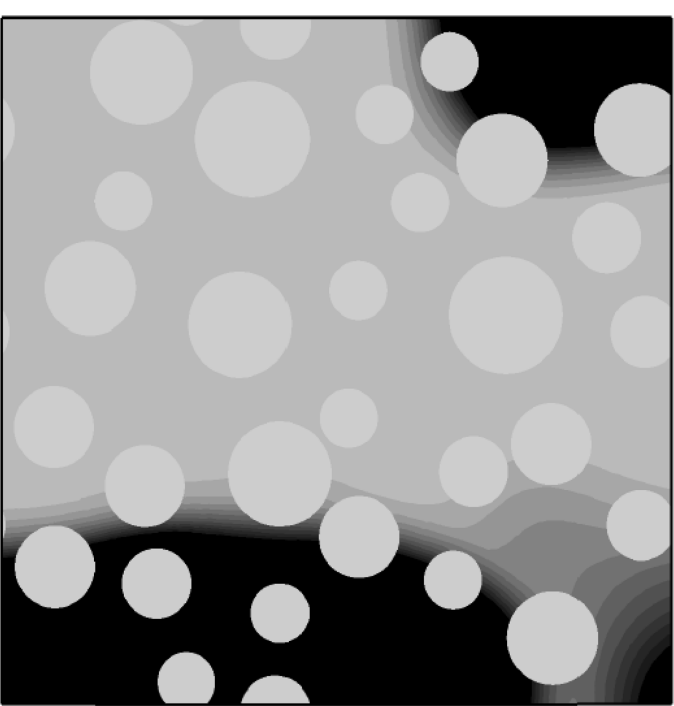

(f)

Fig. 13 Distribution of non-local softening strain measure for various specimen sizes and stress-strain curves from Fig. 10(b) using varying characteristic length approach (reference unit size $15 \times 15 \mathrm{~mm}^{2}$, characteristic length according to Eq. (11), aggregate density $\rho=30 \%$ ) 


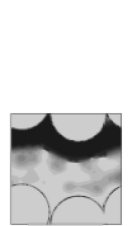

(a)

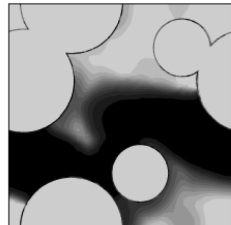

(b)

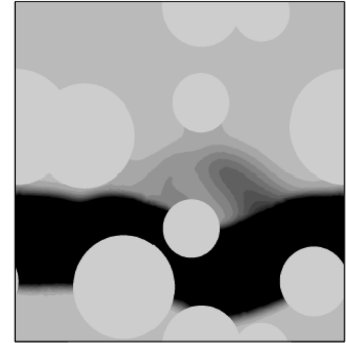

(c)

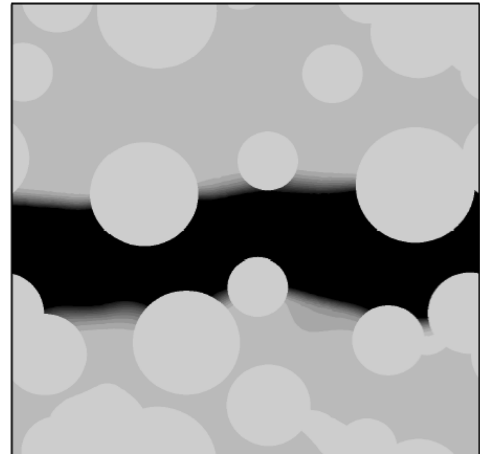

(d)

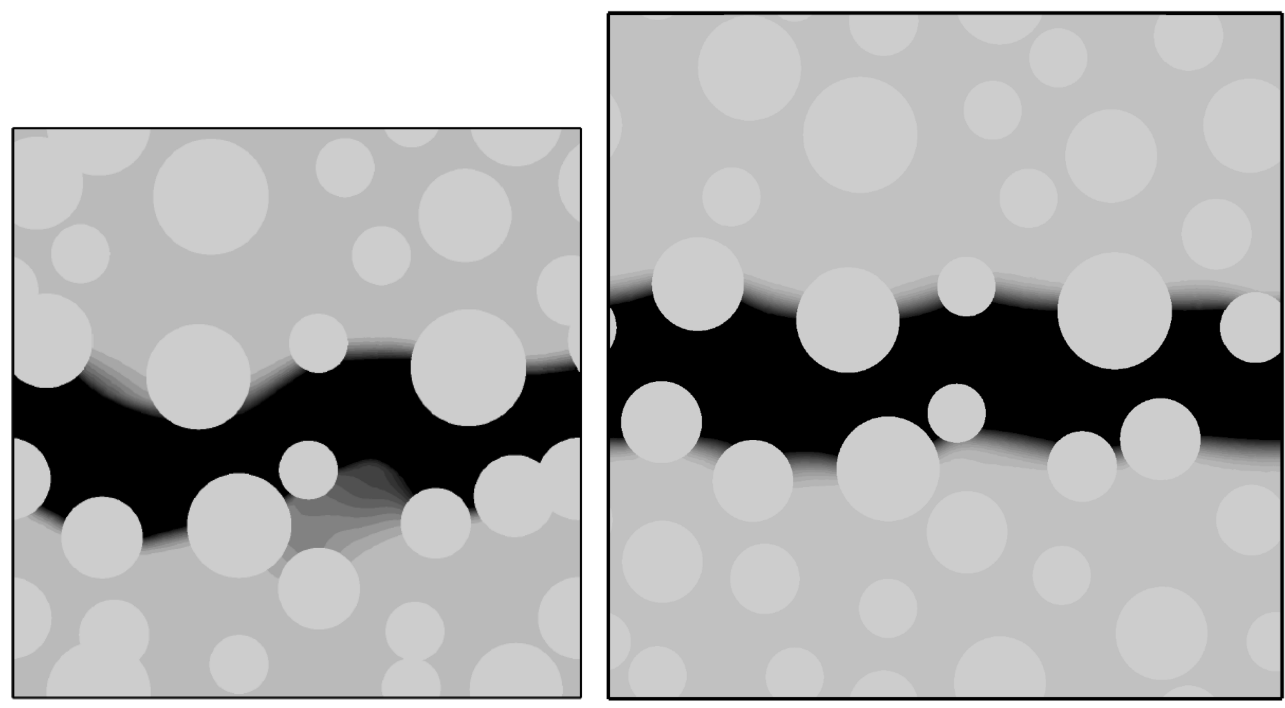

(e)

(f)

Fig. 14 Distribution of non-local softening strain measure for various specimen sizes and stress-strain curves from Fig. 11(a) using varying characteristic length approach (reference unit size $30 \times 30 \mathrm{~mm}^{2}$, characteristic length according to Eq. (12), aggregate density $\rho=30 \%$ )

The expectation value and standard deviation of the unit fracture energy $g_{f}=G_{f} / w_{c}$ versus the specimen height $h$ are demonstrated in Fig. 16. With increasing cell size, the value of $g_{f}$ stabilizes for the unit cell of $15 \times 15 \mathrm{~mm}^{2}$.

\section{Conclusions}

The 2D results of our plane strain FE simulations under tensile loading of softening quasi-brittle materials with a random heterogeneous three-phase structure revealed the following points:

- The representative volume element (RVE) cannot be defined in quasi-brittle materials with a standard averaging approach (over the entire material domain) due to occurrence of a localized zone whose width is not scaled with the specimen size. The shape of the stress-strain curve 


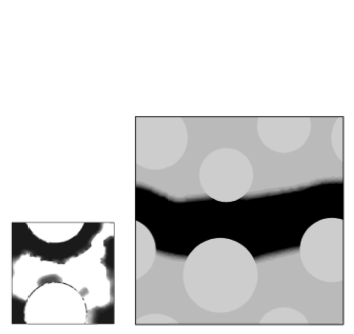

(a)

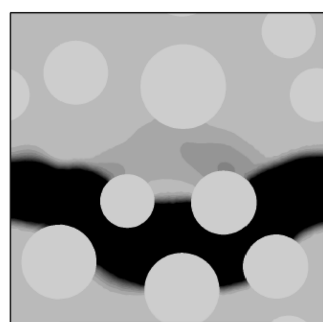

(c)

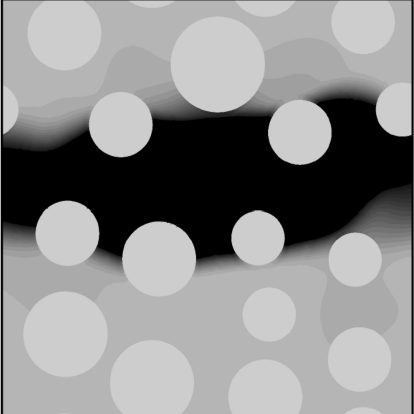

(d)

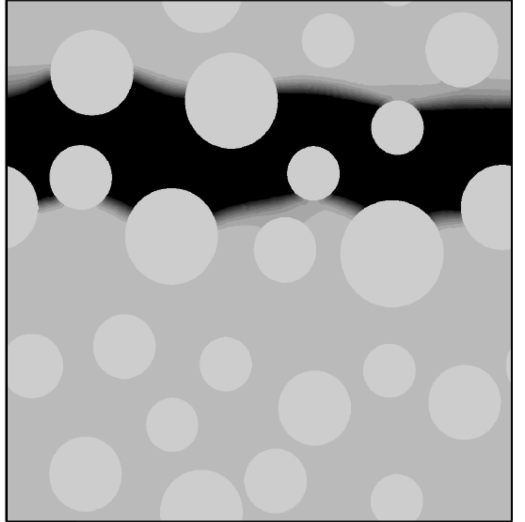

(e)

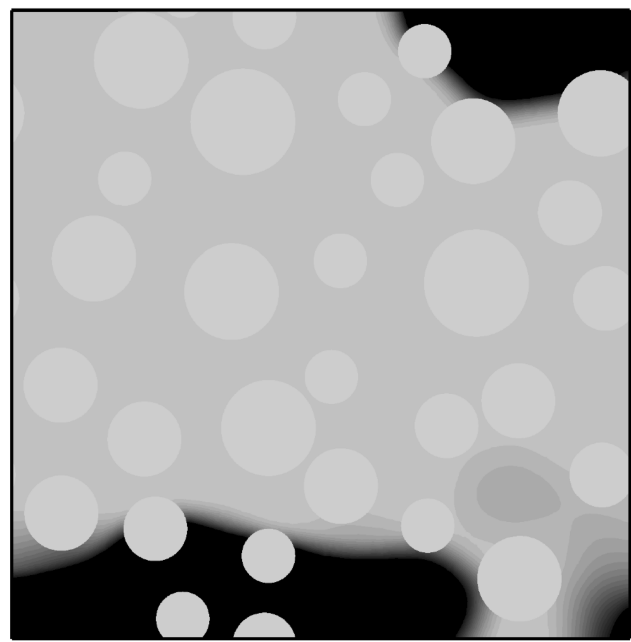

(f)

Fig. 15 Distribution of non-local softening strain measure for various specimen sizes and stress-strain curves from Fig. 11(b) using varying characteristic length approach (reference unit size $30 \times 30 \mathrm{~mm}^{2}$, characteristic length according to Eq. (12), aggregate density $\rho=30 \%$ )

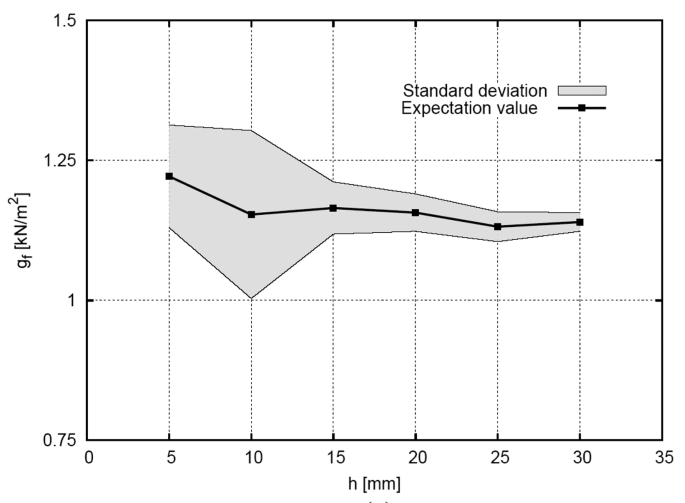

(a)

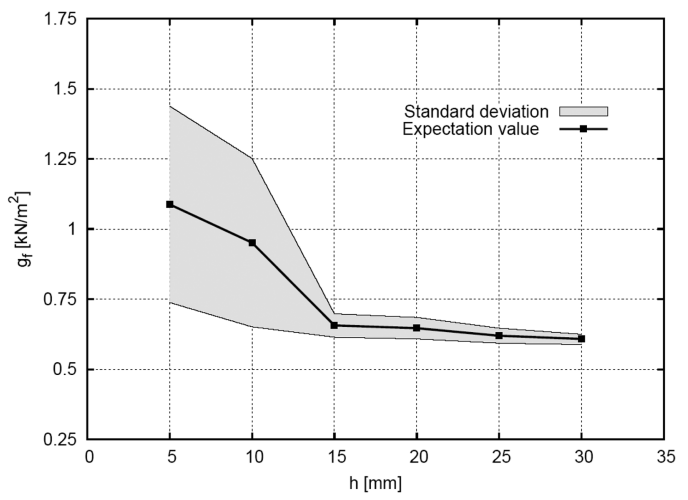

(b)

Fig. 16 Expected value and standard deviation of unit fracture energy $g_{f}$ versus specimen height $h$ using varying characteristic length approach: (a) reference cell size $15 \times 15 \mathrm{~mm}^{2}$, (b) reference cell size $30 \times 30 \mathrm{~mm}^{2}$ (aggregate density $\rho=30 \%$ ) 
depends on the specimen size beyond the elastic region.

- The 2D representative volume element (RVE) can be determined in quasi-brittle materials using both a localized zone averaging approach and a varying characteristic length approach. In the first case, the averaging is performed over the localized domain rather than over the entire domain, by which the material contribution is swept out. In the second case, the averaging is performed over the entire domain with a characteristic length of micro-structure being scaled with the specimen size. In both cases, convergence of the stress-strain diagrams for different RVE sizes of a softening material is obtained for tensile loading. The size of a two-dimensional statistically representative volume element is approximately equal to $15 \times 15 \mathrm{~mm}^{2}$.

The FE calculations will be continued. The representative volume element (RVE) will be determined for shear and mixed mode loading.

\section{Acknowledgments}

Research work has been carried out within the project: "Innovative ways and effective methods of safety improvement and durability of buildings and transport infrastructure in the sustainable development" financed by the European Union.

\section{References}

Bažant, Z.P. and Pijauder-Cabot, G. (1989), "Measurement of characteristic length of non-local continuum", $J$. Eng. Mech. - ASCE, 115(4), 755-767.

Bažant, Z. and Planas, J. (1998), Fracture and size effect in concrete and other quasi-brittle materials, CRC Press LLC, Boca Raton.

Bažant, Z.P. and Jirasek, M. (2002), "Nonlocal integral formulations of plasticity and damage: survey of progress", J. Eng. Mech. - ASCE, 128(11), 1119-1149.

Bažant, Z.P. and Novak, D. (2003), "Stochastic models for deformation and failure of quasibrittle structures: recent advances and new directions", Computational Modelling of Concrete Structures EURO-C (eds.: N. Bicaniæ, R. de Borst, H. Mang and G. Meschke), 583-598.

Bobiński, J. and Tejchman, J. (2004), "Numerical simulations of localization of deformation in quasi-brittle materials with non-local softening plasticity", Comput. Concrete, 1(4), 433-455.

Bobiíski, J. and Tejchman, J. (2010), Continuous and discontinuous modeling of cracks in concrete elements, Modelling of Concrete Structures (eds. N. Bicanic, R. de Borst, H. Mang, G. Meschke), Taylor and Francis Group, London, 263-270.

Drugan, W.J and Willis, J.R. (1996), “A micromechanics-based nonlocal constitutive equations and estimates of representative volume element size for elastic composites", J. Mech. Phys. Solids, 44(4), 497-524.

Evesque, P. (2000), "Fluctuations, correlations and representative elementary volume (REV) in granular materials", Powders Grains, 11, 6-17.

Gitman, I.M., Askes, H. and Sluys, L.J. (2007), "Representative volume: existence and size determination", Eng. Fract. Mech., 74(16), 2518-2534.

Gitman, I.M., Askes, H. and Sluys, L.J. (2008), "Coupled-volume multi-scale modelling of quasi-brittle material", Eur. J. Mech. A - Solid, 27(3), 302-327.

He, H. (2010), "Computational modeling of particle packing in concrete", $\mathrm{PhD}$ thesis, Delft University of Technology.

Hill, R. (1963), "Elastic properties of reinforced solids: some theoretical principles", J. Mech. Phys. Solids, 11(5), 357-372.

Jirasek, M. and Marfia, S. (2005), "Non-local damage model based on displacement averaging", Int. J. Numer. 
Meth. Eng., 63(1), 77-102.

Kanit, T., Forest, S., Galliet, I., Mounoury, V. and Jeulin, D. (2003), "Determination of the size of the representative volume element for random composites: statistical and numerical approach", Int. J. Solids Struct., 40, 3647-3679.

Kouznetsova, V.G., Geers, M.G.D. and Brekelmans, W.A.M. (2004), "Size of representative volume element in a second-order computational homogenization framework", Int. J. Multiscale Comput. Eng., 2(4), 575-598.

Katchanov, L.M. (1986), Introduction to continuum damage mechanics, Dordrecht: Martimus Publishers.

Kozicki, J. and Tejchman, J. (2008), "Modeling of fracture processes in concrete using a novel lattice model", Granular Matter, 10(5), 377-288.

Le Bellěgo, C., Dube, J.F., Pijauder-Cabot, G. and Gerard, B. (2003), "Calibration of nonlocal damage model from size effect tests", Eur. J. Mech. A - Solid, 22(1), 33-46.

Lilliu, G. and van Mier, J.GM. (2003), "3D lattice type fracture model for concrete”, Eng. Fract. Mech., 70(7-8), 927-941.

Marzec, I., Bobiński, J. and Tejchman, J. (2007), "Simulations of crack spacing in reinforced concrete beams using elastic-plastic and damage with non-local softening", Comput. Concrete, 4(4), 377-403.

Nguyen, V.P., Lloberas Valls, O., Stroeven, M. and Sluys, L.J. (2010), "On the existence of representative volumes for softening quasi-brittle materials", Comput. Method. Appl. M., 199, 3028-3038.

Nielsen, A.U., Montiero, P.J.M. and Gjorv, O.E. (1995), "Estimation of the elastic moduli of lightweight aggregate", Cement Concrete Res., 25(2), 276-280.

Peerlings, R.H.J., de Borst, R., Brekelmans, W.A.M. and Geers, M.G.D. (1998), "Gradient-enhanced damage modelling of concrete fracture", Mech. Cohesive-Frictional Mat., 3(4), 323-342.

Pijauder-Cabot, G and Bažant, Z.P. (1987), "Nonlocal damage theory", J. Eng. Mech. - ASCE, 113(10), 15121533.

Sengul, O., Tasdemir, C. and Tasdemir, M.A. (2002), "Influence of aggregate type on mechanical behaviour of normal- and high-strength concretes", ACI Mater. J., 99(6), 528-533.

Simo, J.C. and Ju, J.W. (1987), "Strain- and stress-based continuum damage models - I. Formulation", Int. J. Solids Struct., 23(7), 821-840.

Simone, A. and Sluys, L. (2004), "The use of displacement discontinuities in a rate-dependent medium", Comput. Method. Appl. M., 193(27-29), 3015-3033.

Skarżyński, Ł . and Tejchman, J. (2009), "Mesoscopic modelling of strain localization in concrete", Arch. Civil Eng. LV, 4.

Skarżyński, Ł., Syroka, E. and Tejchman, J. (2009), "Measurements and calculations of the width of the fracture process zones on the surface of notched concrete beams", Strain, doi: 10.1111/j.14751305.2008.00605.x.

Skarżyński, Ł. and Tejchman, J. (2010), "Calculations of fracture process zones on meso-scale in notched concrete beams subjected to three-point bending", Eur. J. Mech. A - Solid, 29, 746-760.

van Mier, J.GM. (2000), "Microstructural effects on fracture scaling in concrete, rock and ice", IUTAM Symposium on Scaling Laws in Ice Mechanics and Ice Dynamics (eds.: J.P. Dempsey and H.H. Shen), Kluwer Academic Publishers, 171-182.

Verhoosel, C.V., Remmers, J.J.C. and Gutierrez, M.A. (2010a), "A partition of unity-based multiscale approach for modelling fracture in piezoelectric ceramics", Int. J. Numer. Meth. Eng., 82(8), 966-994.

Verhoosel, C.V., Remmers, J.J.C., Gutieerrez, M.A. and de Borst, R. (2010b), "Computational homogenization for adhesive and cohesive failure in quasi-brittle solids", Int. J. Numer. Meth. Eng., 83, 1155-1179.

$C C$ 